

Journal of Management and Financial Sciences
Volume XII

Issue 36 (March 2019)

pp. $9-29$

Warsaw School of Economics

Collegium of Management and Finance

\title{
Aquarium: augmented knowledge and wisdom in the age of the Fourth Industrial Revolution
}

\begin{abstract}
The first two decades of the 21st century witnessed the emergence of technical and technological solutions that have enabled digital transformations in the global economy. Registration of unstructured data and bringing them together into large datasets have enriched the cognitive process comprising traditional generation of human knowledge and the digital transformation of data into information and then into industrial knowledge. As a result, we obtain augmented knowledge. Yet, robots and bots (i.e., a device which, unlike a robot, is not connected with mechanisms and other peripheral devices) fuelled by technologies collectively referred to as artificial intelligence, primarily by the machine learning technology, are not able to develop wisdom. That is because robots and bots operate only within two dimensions: perception and context, while a human being has his/her autonomous and subjectively defined axiological system, which shapes his/her capacity to make value judgements and generate wisdom. This system is the third dimension in the aquarium with the glass front wall and the remaining three walls carved in stone. It provides stability ensured by a solid foundation of an axiological system that is thousands of years old and has been approved by the entire global community.

Subjectivity of value judgements made by individuals and social groups produces a great variety of assessments of available knowledge. That is evidenced, inter alia, by decisions about the use of nuclear energy or decisions regulating free access to personal data and interfering with private life.
\end{abstract}

Keywords: cognitive process, axiological system, knowledge and wisdom, digital technologies, artificial intelligence

JEL Classification Codes: D83, D91, O33 


\section{Introduction}

The notion of artificial intelligence has been used increasingly more widely in the specialist subject-matter literature and in the media. For the time being, Europeans have rather little to offer when it comes to the advancement of digital technologies because, with the exception of China and the USA, where in 2017 outlays on the development of such technologies amounted to USD 7.3 bn and USD 5.8 bn respectively, the rest of the world allocated as little as USD 2.0 bn [Steingart, 2018] for this purpose. Initiatives geared towards launching new ambitious projects were proposed, e.g., by Emmanuel Macron, President of France (in 2017) and Lars Klingsbeil, Secretary General of the SPD (in 2018). In November 2018 the Federal Government of Germany announced the strategy titled "AI Made in Germany", [AI - a brand for Germany, 2018] which may be seen as the beginning of the ambitious project of technology development in Germany motivated by the wish to keep up with the United Kingdom, where almost 200 research projects focused on machine learning (the highest number in European countries) were carried out over the period 2012-2016. Whether European academic and business community will actually be able to successfully face their competitors in the global market, we will surely learn as early as in the third decade of the $21^{\text {st }}$ century. At that time, the implementation of 5G, a new telecommunication technology, will ensure dramatically better conditions for data exchange in a wireless network and support the propagation of the Internet of Things.

The Internet, today used mainly by users of available digital technologies, also the Internet of Things, which will enable the exchange of data between devices without human interference, will open the door to the dissemination of technology that we commonly refer to as "artificial intelligence". In order to make an autonomous value judgement of artificial intelligence and the effects of its dissemination, we need to reflect on the changes in the cognitive process connected with human activity (human) and systems created by it (industry). Due to the comprehensiveness of processes addressed in this paper, we will be using interdisciplinary terms deployed in the new discipline of science called "Cognitive Science".

This paper analyses the meaning of the following basic terms:

- data;

- information;

- knowledge;

- wisdom.

Apparently, without understanding the above terms and accepting that today their meaning undergoes deep transformations, we cannot contemplate this specific civilisation achievement, which colloquially is equated with the emergence and deployment of artificial intelligence. Further deliberations suggest that the traditional understanding of the above terms does not allow capturing the specificity of the social and economic system in the age of the Fourth Industrial Revolution. The Fourth Industrial Revolution is about robots and bots offering 
support to intellectual activities of homo sapiens. In the previous centuries three industrial revolutions brought in new technical and organisational solutions, facilitated physical work to humans and transformed the environment. Nowadays, we observe the growth and dissemination of digital technologies, within which (increasingly more) decisions are taken over by systems created by a human being that operate without human interference.

Data may be created by people and autonomously recorded by various devices. If human body temperature is measured by a digital thermometer, it gets recorded by the device. Recorded data can be displayed on the screen, printed out or presented as voice messages. Absolute numerical value, e.g., $38.5^{\circ} \mathrm{C}$ or $101.3^{\circ} \mathrm{F}$, becomes data but it does not inform as whether we are dealing with a disease or not and, if yes, what kind of disease. If the measurement has been taken for someone who has just got sun tanned, her/his body temperature could be elevated as a result of being temporarily exposed to an external heating source. This data, however, may indicate that the person in question is sick and fever is one of the symptoms of a disease.

Undoubtedly, information in the form of a collection of processed data can be created by a human being. In the light of the discussions about the advancements of artificial intelligence we need to decide whether information may be created by an automated device or a computer system in the cloud, i.e. by a robot and a bot. A physician who measures body temperature takes account of a variety of circumstances and by applying his/her professional knowledge, he/she may decide if the person exhibits all the symptoms of a disease. Should we really leave diagnosing to a robot or a bot? Making a device equipped with adequate software capable of generating information raises many questions. The specialist literature points to medicine as an area in which robots and bots may prove especially useful if deployed in diagnostics.

The situation gets much more complicated if we consider generating knowledge. Man is able to create knowledge although the course and effects of the process are subject to the plethora of scientific discussions. Putting it simply, knowledge is generated from views emerging after theoretical analysis has been completed or empirical experiences have been collected. These views are further criticised as to the adopted assumptions and the correctness of analysis carried out to falsify the presented view [Magee, 1998, p. 16]. In the light of the reports about the substance of the development of digital technologies, it is justified to address the question whether recording huge amounts of data, transforming them into information, and synthesizing information to use it in an induction algorithm may generate knowledge. The process is intended to be taking place automatically, which could be regarded as knowledge generation by robots and bots. Based on critical analysis of the synthesis of individual conclusions, we would obtain generalising conclusions of universal importance [Popper, 2002, p. 4]. The IBM Watson project launched in 2006 and the use of the results of analyses conducted within the programme may be seen as an example of knowledge generation in a technologically advanced device equipped with software dedicated to the accomplishment of specific tasks.

Now we shall examine the notion of wisdom. Is the announced plan to allow autonomous vehicles, i.e., vehicles meeting the requirements of the fifth automation level drive on open roads achievable within one or two decades? Heralds of this idea are convinced that 
such a complicated vehicle will be running on public roads at the speed of, e.g., $120 \mathrm{~km} / \mathrm{h}$ and will be able to autonomously and independently select the route. It will also decide if and when to stop to avoid creating dangers to other road users and to the environment. An autonomous vehicle will be an "intelligent" device able to predict and perform complex and unprogrammed tasks [Bertoncello, Husain, Möller, 2018, p. 2]. Should such a mobile robot represent wisdom understood as human capability to make independent judgements and take decisions dictated by them?

Considerations outlined below are an original attempt to describe changes in the cognitive process that take place as a result of advancements in technology. The description discusses the reasons and consequences of changes in the meaning of traditional notions that are taking place during the Fourth Industrial Revolution. Original considerations focus on how augmented knowledge is generated as it comprises, or potentially may comprise, both human knowledge generated and absorbed by human beings and industrial knowledge generated and acquired by devices: robots and bots.

By introducing the term "aquarium" into these considerations, we intend to facilitate the understanding of the idea according to which human wisdom is shaped by a variety of factors, which include knowledge but also an equally important axiological system and motivation, ability to act creatively, subjective judgement, emotions and propensity to exhibit altruistic behaviour, all of which depend on individual attitudes. These factors are absent from operations performed by robots and bots. As observed by H. Volland, IT systems, which in terminals use the 3D-Printing technology are amazing because they can produce a painting with original features that makes references to top accomplishments of genial artists like Rembrandt [Volland, 2018]. Yet, the so far conducted analyses of the ramifications of digital technologies used to create artificial intelligence suggest that automatic devices cannot acquire and exhibit wisdom, because their operations relate to only two aspects: perceptions and context. They use recorded and processed data, generate information and, in the next step, they avail themselves of results of the syntheses of earlier analyses, i.e., specific knowledge generated within the system.

Considerations are supplemented with the examination of two case studies of knowledge generation and use. Both tackle issues of paramount importance for the growth of economy in the Fourth Industrial Revolution: energy policy and data management, including personal data.

\section{Digital technologies and digital transformation}

Since the early 21 st century we have observed an exceptionally rapid growth of digital technologies and other technologies relating to different areas of social and economic activities. In accordance with the Law of Disruption formulated in 2011 and presented in a graphic form in Figure 1, the rate of technological advancements in principle outperforms the rate of social, business, and political transformations. Many circles are anxious about the growing 
gap between technological capabilities and the ability of society to absorb the effects of these technologies, which they see as a threat to the global community in terms of their impact upon the shape of the social order.

\section{Figure 1. The law differentiating the rate of disruptive technological transformations} and the rate of social, economic, and political transformations

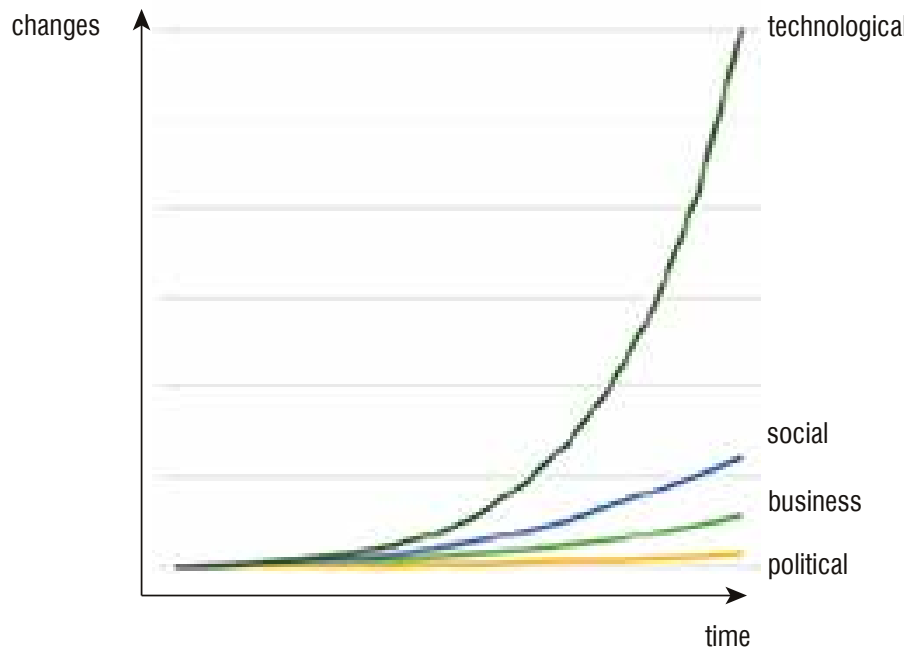

Source: own compilation based on L. Downes, 2011. The Law of Disruption Occupies Wall Street. Forbes 16.10.2011. Retrieved from: www.forbes.com [accessed: 14.02.2017].

Digital technologies occupy a special place amongst all technologies that are being developed currently. Digital transformation has been gaining meaningful and original features because it includes technologies able to facilitate human intellectual effort or even to replace it. Hence, we may legitimately see the current era as the Fourth Industrial Revolution, completely different from the three previous ones, which either alleviated physical burden or totally replaced humans in physical activities. The different nature of the Fourth Industrial Revolution is also evidenced by a new situation in which a human being is no more perceived as a sole creator of knowledge, because IT networks have advanced so much that machine learning technologies deployed in them may produce new knowledge, previously unknown and not acquired by human beings.

An ambitious goal to build an intelligent "machine" that would successfully replace or simulate human intellectual abilities was set in the mid- $20^{\text {th }}$ century. ${ }^{1}$ Researchers, who responded to John McCarthy's invitation and took part in a workshop at Dartmouth College, got engaged

1 The study is to proceed on the basis of the conjecture that every aspect of learning or any other feature of intelligence can in principle be so precisely described that a machine can be made to simulate it. An attempt will be made to find how to make machines use language, form abstractions and concepts, solve kinds of problems now reserved for humans, and improve themselves. Excerpts from an invitation sent on 31.08.1955. Retrieved from: https://www.livinginternet.com/i/ii_ai.htm [accessed: 23.09.2018]. 
in a long debate in the summer of 1956 and proposed a new term: "artificial intelligence" (AI). A vision of a machine equipped with abilities equal to human ones or even superior had been promoted since the first half of the 20th century by writers or film directors who created the imaginary world filled with beings able to perform superhuman acts. Isaac Asimov in a story titled Runaround published in 1942 formulated three laws which, if observed, could protect a man against harmful, almost destructive machines [Nida-Rümelin, Weidenfeld, 2018]. Promotion of the image of machines and other beings existing on the borderland between the real and virtual world able to engage into activities hostile to humans stirred up strong emotional attitudes among the global community as to how we respond to the achievements of digital technologies. Fears of a potential threat from robots and bots equipped with "artificial intelligence" are quite common and the hope that the advancement in digital technologies may facilitate reaching the state of happiness (understood as a state of well-being and satisfaction with life [Tatarkiewicz, 1990, p. 24]) to individuals and to the mankind is very slim.

A breakthrough in the development of digital technologies took place after innovative technical solutions had been put in place and new services emerged, which quickly won the approval of consumers and businesses dealing with manufacturing and distributing goods and traditional services. Innovations that marked the beginning of the age of the Fourth Industrial Revolution are presented in Table 1.

Table 1. Innovations marking the beginning of the Fourth Industrial Revolution

\begin{tabular}{|l|c|}
\hline \multicolumn{1}{|c|}{ Innovation } & Year \\
\hline $\begin{array}{l}\text { The launching of Facebook, the first social medium, which allowed collecting data about billions of consumers who } \\
\text { are its users }\end{array}$ & 2004 \\
\hline $\begin{array}{l}\text { The launching of Amazon Web Service, the first platform offering cloud computing services, which allows collecting } \\
\text { and processing practically unlimited amounts of data at the speed that enables to control processes, in which action } \\
\text { and reaction to it should happen almost simultaneously }\end{array}$ & 2006 \\
\hline \begin{tabular}{l} 
The first iPhone placed in the market, a mobile device comparable to technologically advanced computers \\
\hline $\begin{array}{l}\text { For the first time major developed economies began to invest more in intangible assets, mainly software, descriptions } \\
\text { of procedures, and training staff who will be using them, than in tangible assets [Haskel, Westlake, 2018, p. 45] }\end{array}$
\end{tabular} & $2006-2008$ \\
\hline $\begin{array}{l}\text { The implementation of effects of R\&D works in the IT sector started to generate revenue which in the short run } \\
\text { outperformed R\&D outlays; such a surplus was not observed in any other industry or service sector while in previous } \\
\text { decades it was not reported at all [Sivaram, 2018, p. 258] }\end{array}$ & since 2010 \\
\hline $\begin{array}{l}\text { Academic centres started to deploy digital machine learning technologies in studies and teaching, including the } \\
\text { M00Cs (Massive Open Online Courses) [Ford, 2015, p. 133] }\end{array}$ & $2011-2013$ \\
\hline $\begin{array}{l}\text { Siemens developed the first European platform which uses the loT to control manufacturing processes in accordance } \\
\text { with the Industry 4.0 concept }\end{array}$ & 2017 \\
\hline $\begin{array}{l}\text { Expected implementation of 5G telecommunication technology, which will enable mobile and stationary devices } \\
\text { connected to the loT to take part in automated control processes in quasi real time [Chafkin, Brustein, 2018] }\end{array}$ & after 2020 \\
\hline
\end{tabular}

Source: own compilation.

In the above list of events a special place belongs to the dissemination of machine learning technology developed already in the 1990s and simultaneous advancements in the three remaining automation technologies applied to processes from the artificial intelligence category included in Table 2. 
Table 2. Major automation technologies

\begin{tabular}{|c|c|c|c|}
\hline Machine-learning algorithms & Robotic process automation & $\begin{array}{c}\text { Voice assistants, chatbots, } \\
\text { and/or cognitive agents }\end{array}$ & $\begin{array}{c}\text { Natural-language processing } \\
\text { and/or generation }\end{array}$ \\
\hline
\end{tabular}

Source: own compilation.

These technologies have advanced so far that we can easily notice their specific features and see how the application of one of them impacts the use of the remaining ones. The clearer are the differences between these technologies, the more experts suggest that in academic and business circles we should avoid the term "artificial intelligence" (de-hyping AI) as, due to associations with literature and works of art, it introduces chaos in the understanding of its effects [Kroeger, 2018]. At the same time, we observe an upward trend in understanding that cognitive science is about interdisciplinary studies presented in Figure 2.

Advancements in technology provide an impulse for business players seeking a market opportunity in proposing new business models. New services are developed and new business models are put in place. As a next step, economy gets transformed and because of the primary importance of the implementation of digital technologies, the process is seen as digital transformation. The process is illustrated in Figure 3.

Figure 2. Links between fields of science brought together in cognitive science

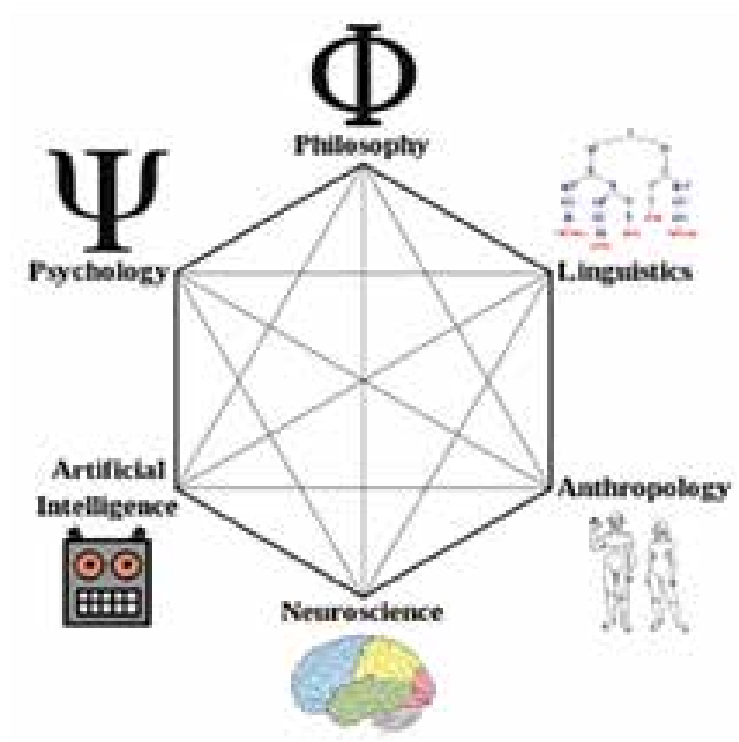

Source: https://en.wikipedia.org/wiki/Cognitive_science [accessed: 09.03.19].

While digital transformation takes place, we can observe the expansion of new market players including service providers who become virtual platforms operators. By using digital technologies as well as technologies from other fields of advancing science and improved know-how, they can expand rapidly. When expanding their business in the virtual world, 
these operators do not have to overcome a barrier known to the analogue world as the barrier to quantitative growth of own tangible assets and they may focus on quick expansion of intangible assets. Data presented in Table 3 show the dominant position of businesses from the digital technologies sector among operators engaged in R\&D.

\section{Figure 3. Changing roles of market participants on the supply side in digital transformation}

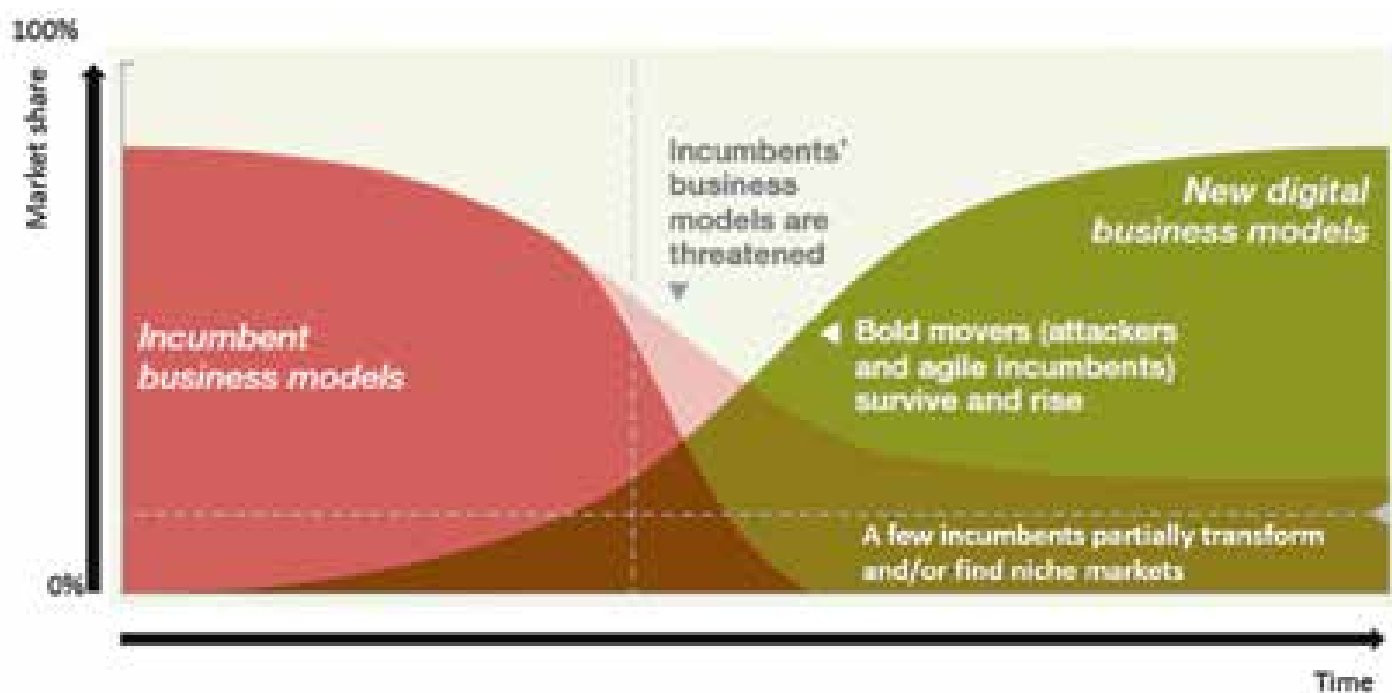

Source: the author's own compilation based on J. Bughin, T. Catlin, M. Hirt, P. Willmott, (2018). Why digital strategies fail. McKinsey Quarterly, January, p. 6.

Table 3. Companies - top R\&D spenders in 2017

\begin{tabular}{|l|l|c|c|}
\hline \multicolumn{1}{|c|}{ Company } & \multicolumn{1}{|c|}{ Country of origin } & R\&D outlays [in USD bn] & $\begin{array}{c}\text { Increase or drop in outlays compared } \\
\text { to 2016 }\end{array}$ \\
\hline Amazon & USA & 20.1 & $+41 \%$ \\
\hline Alphabet/Google & USA & 14.7 & $+19 \%$ \\
\hline Samsung & South Korea & 13.2 & $+14 \%$ \\
\hline Intel & USA & 11.6 & $+3 \%$ \\
\hline Volkswagen & Germany & 11.6 & $+1 \%$ \\
\hline Microsoft & USA & 11.6 & $+9 \%$ \\
\hline Apple & USA & 10.3 & $+15 \%$ \\
\hline Roche & Switzerland & 10.2 & $+2 \%$ \\
\hline Johnson\&Johnson & USA & 9.4 & $+16 \%$ \\
\hline Merck\&Co. & USA & 9.1 & $+1 \%$ \\
\hline
\end{tabular}

Source: the author's compilation based on: U. Sommer, (2018). Diese Zahlen zeigen, weshalb US-Tech-Konzerne immer mächtiger werden. Handelsblatt 15.08.2018. Retrieved from: www.handelsblatt.com [accessed: 15.08.2018]. 


\section{Flat world of knowledge generation and the emergence of augmented knowledge}

In the age of the Fourth Industrial Revolution an increasingly bigger challenge is posed by the recognition of the course of cognitive process and generation of knowledge. The number of participants to these processes and proposed solutions is increasing. Advancements in the dissemination of new technologies have revealed solutions which, if applied, produce concrete effects. Thus, we may provide a detailed description followed by an increasingly more meticulous analysis of these solutions and conclusions.

In the virtual world all events can be recorded and each such event generates digitally recorded data. After smartphones - which record data about human behaviour - have been placed on the market and got disseminated, virtual platform operators have received access to huge amounts of data that can be referred to as HUMAN BIG DATA. Operators have accomplished their goal and acquired access to data, often intimate ones, as customers got allured by the promise of being able to "reach your close friends and family members as quickly as possible with the biggest number of messages about yourself" plus no charge for the service under the "freemium" business model [Lessin, 2018].

By the end of the second decade of the 21 st century conditions have emerged to collect big amounts of data about how devices operate. Because sensors are being used more and more universally and because the industrial Internet of Things is expanding, each event can be identified with respect to place and time, quality, status or value of the measured object. The door has been opened for creating huge data resources that would reflect the behaviour of machines and other devices operating in the real world as well as the behaviour of autonomous systems operating in the virtual world. These resources can be referred to as INDUSTRIAL BIG DATA.

Accessibility of these resources:

- HUMAN BIG DATA

- INDUSTRIAL BIG DATA

creates conditions for the application of the Big Data Analysis methodology and other advanced methods of business intelligence (BI), such as filtering, validation, and processing of data. The more we expand the scope of perception of events and occurrences and the scope of context in these analyses, the more data is used to generate information. The scope of perception and context are decisive for transforming data into information.

The substance of data transformation into information may be little understandable to someone who does not have adequate knowledge and experience in using digital technologies. Many people are not aware that information handling without paying attention to data necessary for information to be generated is a natural human behaviour. Someone who takes, e.g., an apple in his/her hand with an intention to eat it intuitively acquires information whether the fruit can be eaten. We organoleptically check if a particular piece of fruit is rape and not rotten. The condition of the fruit is assessed while we cannot give a detailed description of the 
condition by informing, e.g., about sugar content. In contrast with a human being, a robot or a bot must collect a lot of data from the examination of physical and biological qualities of each piece of fruit and confront them with reference data, identify deviations, and analyse if they remain within the tolerance interval. It is a multistage analysis of an object, fruit in this case, by a robot or bot, after which we receive a message telling us whether the fruit is edible or not. Instead of a light signal sent out by a diode that emits green light, a voice message can be generated: "this apple is edible".

A human being - like a robot and bot - undertakes the first stage of the cognitive process depicted in Figure 4, being completely unaware of the fact that information he/she seeks to obtain is generated through data recording and processing.

Figure 4. Stages of the cognitive process including data transformation into information (stage 1) and transformation of information into knowledge (stage 2)

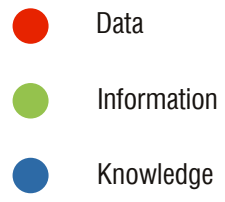

Stage 1

$\Longrightarrow$ Stage 2



Source: own compilation.

The second stage of the cognitive process consists in information transformation into knowledge. The analysis of cumulated information, identifying causal relationships between pieces of information, and, above all, the synthesis of many pieces of information originating from different areas and time periods generate knowledge. If, e.g., registered data are numerical values (expressed in natural units) concerning food that people buy every day at retailers in a specific region and time, such as bakery products, fruit and vegetables, fish, dairy products, meat and cold cuts, algorithms may help to extract information about monthly flows of these food products from producers to households through distribution channels. Further, the collected data and information created from them are analysed also by algorithms and results of such analyses are synthesised; at the end of the cognitive process we end up with a report containing the knowledge about the size and structure of consumption. The scope and level of details of this piece of knowledge may be enriched with the examination of the data and 
information that could be received from Smart Home systems, i.e. using sensors that register, inter alia, amounts of individual products stored in refrigerators as well as in other storing places or devices, periods for which they are stored and sensors that register the amount and structure of household waste. In the above example, the combination of HUMAN BIG DATA and INDUSTRIAL BIG DATA analyses brings us up to the level of context totally unachievable to researchers of consumer behaviour from the past, who could avail themselves only of analogue methods, e.g., questionnaires filled out by consumers and their quantitative analysis.

The growth of machine learning technology used in data processing includes a validation procedure for obtained results. Validation takes place through the confrontation of automatically received results. One of the solutions may be the use of the Generative Adversarial Networks method which ensures parallel machine learning processes in two systems out of which one "is looking for" new results, while the other one is trying to falsify them [Volland, 2018].

The above considerations authorise us to conclude that the transformation of data into information at the first step of the cognitive process and then getting information transformed into knowledge in the second step, takes place within the framework of processes dependent on just two variables: the scope of perception and context, which in Figure 4 are represented by axes $\mathrm{X}$ and $\mathrm{Y}$ respectively. It is also reasonable to claim that the transformation of data into information and then into knowledge proceeds in a flat world described by only two dimensions.

The presence of INDUSTRIAL BIG DATA that include data recorded by automated devices that monitor occurrences and events in the real and virtual world, i.e. by robots and bots, opens up new possibilities in the age of the Fourth Industrial Revolution. By using these data, we may generate information and knowledge about how the INDUSTRIAL WORLD operates, the world that has been created by humans but whose operations proceed without human interference. Table 4 presents relationships in the HUMAN WORLD and INDUSTRIAL WORLD.

Table 4. Data and information coming from diverse sources and areas of activity and generating HUMAN KNOWLEDGE and INDUSTRIAL KNOWLEDGE as elements of augmented KNOWLEDGE

\begin{tabular}{|l|l|l|}
\hline \multicolumn{1}{|c|}{ Activity areas } & \multicolumn{1}{|c|}{ HUMAN WORLD } & \multicolumn{1}{c|}{ INDUSTRIAL WORLD } \\
\hline Data loggers & $\begin{array}{l}\text { Smartphones, wearable devices, stationary } \\
\text { and mobile computing devices, voice recording } \\
\text { devices (e.g. Echo Amazon), and audio and video } \\
\text { recording devices (e.g. Echo Look Amazon) }\end{array}$ & $\begin{array}{l}\text { Sensors } \\
\text { Data recording systems, e.g. in Smart Home } \\
\text { (recorders placed in household appliances) or } \\
\text { in vehicles equipped with active driver-assistance } \\
\text { systems (including recorders placed in a quasi- } \\
\text { autonomous vehicle) }\end{array}$ \\
\hline Nature of data & Human behaviour (behaviour, time and place) & Status of devices and virtual systems \\
\hline Nature of information & $\begin{array}{l}\text { Human behaviour (an integrated picture "here } \\
\text { and now") }\end{array}$ & $\begin{array}{l}\text { Acting in accordance with the programme or } \\
\text { existing deviations (their description) }\end{array}$ \\
\hline Nature of knowledge & $\begin{array}{l}\text { Collective behaviour of, e.g. groups classified } \\
\text { to individual market segments }\end{array}$ & Maintenance procedures, predictive maintenance \\
\hline $\begin{array}{l}\text { Components of augmented } \\
\text { KNOWLEDGE }\end{array}$ & HUMAN KNOWLEDGE & INDUSTRIAL KNOWLEDGE \\
\hline
\end{tabular}

Source: own compilation. 
Works on the development of knowledge generation systems in the INDUSTRIAL WORLD area are so advanced that experts draw attention to the probability of a situation in which man loses control over the content of INDUSTRIAL KNOWLEDGE. Perhaps computer systems programmed by a man already hold knowledge resources that have gone far beyond human perception capabilities and are inaccessible to us. One could make a long list of barriers to the absorption of augmented KNOWLEDGE generated as a result of integration of HUMAN KNOWLEDGE with INDUSTRIAL KNOWLEDGE. Firstly, some of these barriers are created by the imperfectness of devices used as interfaces that ensure mutual communication between man and a system developed by him or her. Such barriers may be gradually eliminated or, at least, their importance should be reduced. However, there is a dramatically more relevant barrier resulting from insufficient human knowledge about how to elicit adequate complex communications (reports) from a system operated on human order [Scheutz, 2018, p. 1].

The above presented idea of how augmented knowledge, i.e. knowledge founded on data recording and processing, is generated and developed, deserves being juxtaposed with K. Popper's views, in which he discredited the induction method as a rational knowledge building methodology [Chmielecki, 1995, p. 54].

Computer systems may generate reports, which traditionally do not address "views" as views can be developed by man able to make only subjective judgements. Data transformation into information and the synthesis of information performed by a computer system programmed by man may produce huge amounts of complex pieces of information within a broad scope of perception and context. In the era of the Fourth Industrial Revolution, it is worth considering a postulate to see certain reports as elements of INDUSTRIAL KNOWLEDGE. Then, knowledge originating from a computer system could be validated by man, provided the human being is able to formulate correct research hypotheses and falsify them. In search for such hypotheses one must ask questions to which no answers can be found in knowledge known to man, i.e. in HUMAN KNOWLEDGE also referred to as "objective knowledge", because knowledge that we have is only hypothetical [Popper, 2002, p. 3]. Experienced researchers in natural sciences, in which research hypotheses need to be validated when conducting empirical studies in a laboratory; being able to formulate questions that bear no relation with previously acquired knowledge is considered the greatest intellectual accomplishment of a researcher [Schatz, 2015].

\section{The third dimension or the aquarium of wisdom}

The fascination with the development of digital technologies exhibited by the visionaries of economic growth in the age of the Fourth Industrial Revolution has made some authors describe the cognitive process up to the moment when wisdom emerges and is reflected in artificial intelligence. Thousands of applications available nowadays in the cloud that can be used by anyone who has got a smartphone are based on the "narrow artificial intelligence". 
In a simplified version, cognitive process, from data recording to the emergence of wisdom and its reflection in narrow artificial intelligence is presented in Figure 5.

\section{Figure 5. Wisdom assisted with narrow artificial intelligence as an outcome of cognitive process, from data through their transformation into information and then into knowledge}



LEVEL OF UNDERSTANDING

Source: own compilation.

The cognitive process sketched in Figure 5 seems simplified so much that it is not credible anymore. This is why we need to introduce some corrections. The same has been observed by some experts from the USA and from China, including Wanli Min, the author of ET Brain, i.e. a technological solution developed by the Alibaba virtual platform operator, the Chinese leader in digital technologies [Scheuer, Mathes, 2018]. We may refer to the postulate to set creative solutions to many problems of the contemporary world in classical tradition and in the notion of rationality linked with it, to human mind, which not only seeks to find means leading to an end in the most efficient way, but also engages into axiological reflection on moral issues and the need to accomplish the highest human goals [Korab-Karpowicz, 2017, p. 9].

In order to comply with this postulate, further considerations on the cognitive process will be enriched by introducing the axiological system as the third dimension in our analysis. While the above deliberations took account of just two dimensions, from now on we will continue with three dimensions in mind. We could propose to take the cognitive process and its two stages depicted in Figure 6 and project it on a plane, which is the front wall of an aquarium. Let the two remaining planes delineate the space contained in the aquarium. If axis $\mathrm{Z}$ represents the axiological system, we may assume that except the front wall, the other walls of the aquarium are made of planes carved in a rock. It means that axis $Z$ is steady as a rock, like the foundations of the axiological system shaped throughout thousands of years of civilisation development. Symbolically, the foundations of the system are laid by the Ten Commandments. 
The level of the imaginary liquid in the aquarium marks the level of augmented KNOWLEDGE, which is composed of HUMAN KNOWLEDGE and knowledge provided by robot/ bot systems (INDUSTRIAL KNOWLEDGE). In the practice of cloud computing we could admit that augmented knowledge is collected by computer systems [Straube, 2018]. Having said that, we must take account of the growth dynamics of INDUSTRIAL KNOWLEDGE connected with the operation of already existing computer systems. They work in real time and generate new knowledge practically continuously.

Figure 6. Aquarium: generating knowledge as a synthesis between the cognitive process carried out by a human being or a computer system capable to generate knowledge and the critical analysis of knowledge by man making his/her subjective value judgement
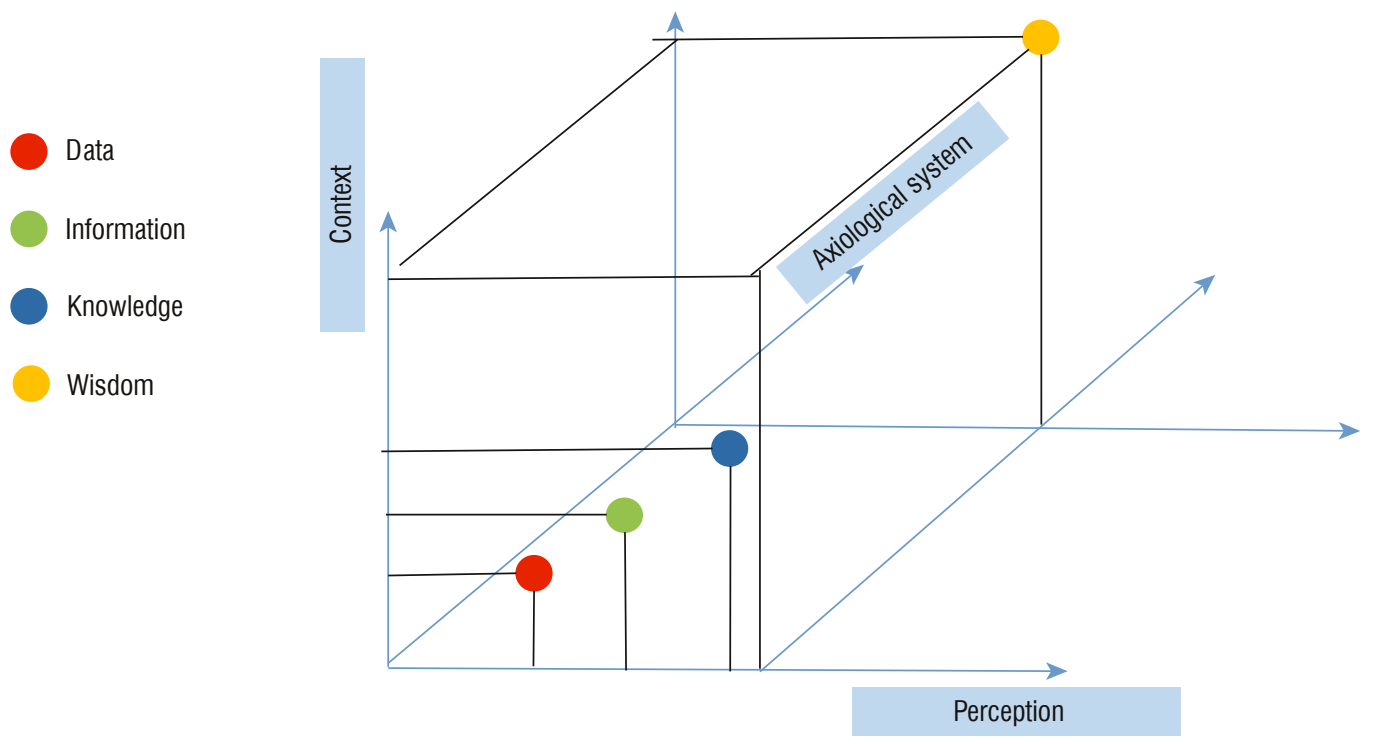

Source: own compilation.

In the aquarium man may strive to penetrate the highest tiers of the liquid. But man does not need the total pool of augmented knowledge at all, because in the modern world we are dealing with specialisation and the failure to absorb complete knowledge by an individual is considered natural. In fact, the absorption of only very limited knowledge may be associated with people who we see as almost genius.

It means man - everyone individually - creates his/her position with regard to the scope of perception and context reflected on the front wall of the aquarium. Yet, the crucial thing is that man - contrary to a robot or bot - is able to penetrate the aquarium drifting away from its front wall. His or her position begins to depend on the development of an individual axio-normative system and self-positioning of his/her own attitude within this system. Wisdom can be seen with reference to the front but also to the remaining walls of the aquarium. One cannot identify an "optimal" or "desired" position, since individuality and capability to get 
(self) satisfaction from adopting different attitudes are human features. They are reflected in individual positions inside the aquarium for different levels of immersion in the liquid and distance from the front wall. The position of every individual is also determined with his/her original, subjective value judgement of situations and processes that he/she perceives in the environment. Wisdom is a human attribute that cannot be acquired by the robot/bot system because by applying digital technologies we do not create either moral attitudes or motivations for such attitudes to develop.

While the size of the front wall of the aquarium (decisive for the aquarium width and height) depends on many objective circumstances, i.e. data resources, information, and augmented knowledge comprising HUMAN KNOWLEDGE and INDUSTRIAL KNOWLEDGE, the length of the aquarium is unlimited as the axiological system is and will remain the product of only and exclusively human imagination (mind).

\section{Different wisdom for equivalent knowledge}

The dissemination of solutions referred to as artificial intelligence has created an environment in which considering the reasons for having attitudes of individuals and communities that differ in principle is fully legitimate. Seemingly, nowadays knowledge transfer proceeds rather quickly and in multiple directions, which is why apart from access to specialist solutions (protected e.g. by patents) people living in different regions of the world may make references to relatively uniform knowledge. Technological leap witnessed in China within the recent three decades confirms that economies that are lagging behind can relatively quickly absorb knowledge and advanced technologies available in other regions to then proceed to the stage in which they start generating their original knowledge and develop the most advanced technologies.

By observing how societies behave, one may realise that there are principal differences with respect to some aspects of knowledge interpretation and implementation of specific solutions in the social and economic system. We should discuss here two examples from completely different fields of social and economic activity. The first is the energy policy pursued by France and Germany, two Member States of the European Union. Energy is a sector dominated with analogue technologies implemented and developed in the times of the Second and Third Industrial Revolution and only modified in the era of the Fourth Industrial Revolution. Apart from new entrants, who implement innovative technologies and generate energy from renewable energy sources, the energy sector is dominated by incumbents, mostly state-owned enterprises whose market position is protected because they get support from public authorities.

The second example is personal data use and protection policy in the transatlantic region and in China. This new economic sector deploys exclusively new digital technologies and services to individual customers are rendered only by new entrants. However, we must not overlook the fact that the market in the transatlantic region is open, while in China access to the market is blocked or at least more difficult to investors and foreign operators and at the same time 
the growth of local players, formally private companies, strongly depends on decisions made by local public authorities subordinated to the communist party.

\section{Energy policy}

Challenges faced by energy policy may be seen from two points of view. The traditional approach focuses on the choice of technology used to generate electricity and on the choice of regions and specific suppliers of energy and equipment used in the energy sector to generate and distribute electricity.

One may not provide convincing arguments that the knowledge about advantages and disadvantages of deploying nuclear energy available in Germany is principally different from the knowledge available in France. Yet, public authorities in these two neighbouring countries influenced by different opinion leaders decided to adopt drastically different strategies vis-à-vis nuclear energy. In Germany the last working reactors will be phased out in 2022, while in France the existing reactors will continue generating energy and new reactors are planned. The share of different components of energy mix in France and Germany in 2017 is presented in Figure 7.

Figure 7. Differences in energy mix in France and Germany in 2017 - percentage share of individual energy sources and technologies of power generation in energy output



Source: own compilation based on France's Overall Energy Mix. Planete Energies 27.08.2018. Retrieved from: www.planete-energies. com [accessed: 24.10.18] and K. Appunn, F. Bieler, J. Wettengel, (2018). Germany's Energy consumption and power mix in charts. Clean Energy Wire 3.04.2018. Retrieved from: www.cleanenergywire.org [accessed: 24.10.2018].

Founded on comparable knowledge, the wisdom of German society tells them to withdraw from nuclear energy, while the wisdom of French society tells them to continue to invest 
in nuclear reactors. Differences in wisdom come from diverse subjective value judgements approved by German and French societies with respect to the following issues:

- public security;

- importance of environmental protection concerns;

- assessing the value of technologies used to generate electricity against a set of soft criteria and taking account of external factors (positive and negative) relating to the use of nuclear energy and other technologies, including those based on coal and lignite combustion;

- collaboration policy with countries-exporters of oil, natural gas and their derivatives.

The deep difference in how energy policy is pursued in France and Germany is one of the reasons why the EU integration has not achieved a level at which the European economy could fully benefit from synergy effects of the application of available knowledge. Looking at the fight for global market share, we may see the dissipation of efforts in the European energy sector as one of the reasons why Europe is relatively little able to compete with the United States and China, two leading economies of our times.

One may come across a completely different account of challenges resulting from the need to ensure access to energy. In the age of the Fourth Industrial Revolution it has become increasingly more obvious that man has made the civilisation dependent on energy supplies. As argued by J. Bezos, a visionary and the richest man on Earth, before the First Industrial Revolution people needed energy just to maintain the body's vital functions, primarily energy required to fuel the brain. Nowadays, human demand for energy, mainly electricity, is incomparable because we use computer systems indispensable for ICT systems to work together with increasingly more popular robots and bots. It is anticipated that, together with the dissemination of digital technologies, demand for electricity will grow globally at a rate that will outperform the capabilities offered by all available energy generation technologies to meet it. Therefore, J. Bezos believes that the major civilisation challenge comes from the ability to acquire new technologies that would let us use energy from the outer space on Earth [Döpfner, 2018]. From this perspective, students at universities at the turn of the second and third decade of the 21 st century will be faced with a challenge to get ready to join the next industrial revolution, when installations on satellites placed in the Earth orbit will become the main sources of electricity to terminals on Earth, also to systems run on digital technologies.

\section{Personal data management}

In the digital economy era insufficient access to data is considered one of the least relevant barriers to business development - in 2017 in the USA only 13\% respondents saw it as such. A major barrier pointed out by $33 \%$ respondents [Goran, LaBerge, Shrinivisan, 2017, p. 2] is posed by cultural challenges and human attitudes. If knowledge is egalitarian, we need to examine how access to data, including personal data relating to private individuals, should be shaped. There is a widespread conviction among the public that today citizens may not enjoy as much privacy as in the past. M. Garbicz, who claims being anonymous in the past 
was rather an exception than a rule, believes this opinion about the position of an individual in the community is utterly ungrounded [Garbicz, 2018]. When people lived in small communities, i.e., in villages, everyone from cradle to grave would live in his/her family circle and among neighbours who knew one another. In regions where Catholic religion prevails, the local priest remains a close confidant of secrets entrusted to him in the confessional, which is why members of the Catholic Church have always approved the absence of total privacy as a standard of social relationships. With migration flows from rural areas to cities and as a result of the Reformation movement in the Church, traditional social bonds evolved. Many people arriving into urbanised regions would become anonymous members of the community. In the era of the Fourth Industrial Revolution the situation has changed dramatically. Increasingly more numerous public spaces and expanding areas of social and economic activities have turned into areas where all events are recorded and data are generated, while individuals have no real impact upon these practices. On top of that, consumers who use the "freemium" business model consciously or unconsciously give consent to record their behaviours as well as physical and emotional states on devices that follow them 24 hours a day in any location. In extreme cases we witness "digital exhibitionism," i.e. recording events that traditionally belong to the intimate realm and purposefully placing them on the Internet (e.g., in social media). Operators of virtual platforms have all or almost all data at their disposal recorded as images (video, photos) or audio content (audio recordings) or results of measurements of the conditions of the body or mental states obtained from wearable devices.

By investigating into how these operators work in the age of the Fourth Industrial Revolution we may come to the conclusion that using the primarily unstructured data these operators can process data to extract big information resources. This view is supplemented by the hypothesis according to which by using machine learning technologies these actors and specialised teams of data analysts who collaborate with them have already implemented narrow artificial intelligence solutions capable to generate INDUSTRIAL KNOWLEDGE. In March 2016 after 16 hours of running, Microsoft - wishing to avoid infringing ethical norms - stopped a project in which Tay bot, based on the analysis of content placed in the social media, began to exhibit an autonomous ability to spout racist comments. Cognitive process aimed at examining messages in the media revealed that a bot may acquire an ability to select information based on recorded and recognised emotional condition of social media users and taking account of their social attitudes. Such conduct of the bot was not anticipated in the algorithm that had been developed by the project authors [Trösch, 2018]. This case may announce situations when knowledge about social media users is generated and their individual attitudes vis-à-vis other people are detected, in particular with respect to those labelled as "aliens" or "enemies".

The outcome of the work of Cambridge-Analytica, a team of analysts who used raw data available on Facebook to create "anti-knowledge," i.e. fake news, resulted in a spectacular scandal. The efficiency with which false content was not only purposefully created but also disseminated to target users lets us conclude that based on data from the social media they 
generated INDUSTRIAL KNOWLEDGE. This knowledge included a precise description of a potential propensity of individual users to uncritically accept content made available to them and, consistently, to make their behaviour, e.g., during presidential elections in the USA, dependent on the intention of operators who distributed this content, knowing the profiles of individual people they target. Operators' actions and, above all, activities of their principals were pursued without the consent of those to whom the fake news was addressed but, even if those addressees wanted to prevent receiving these messages, they had no effective tools to express their will [Henkel, 2018].

Perceived dangers to social order and examples of individual people are increasingly more often triggering postulates to restrict the freedom of virtual platform operators as to the use of data available to them. Visionaries and digital technology leaders seem to be divided over this issue. The group of supporters of the idea of developing global regulations includes, e.g., T. Cook, the CEO of Apple, who in October 2018 when visiting the European Parliament warned against tolerating practices of "total surveillance" exercised by operators, such as Facebook or Google, active predominantly in the transatlantic social and economic system [Hoppe, Weddeling, 2018]. Their conduct, driven by profit, does not differ much from what Chinese operators do by engaging in the dynamic growth of digital technologies in their country to create a surveillance and reputation assessment system (Social Credit System [Kędzierski, 2018]) promoted and monitored by the communist party and used to assess Chinese citizens and people coming to China [Hua, Jahn, Kerkmann, Matthes, Scheuer, Weddeling, 2018].

\section{Summary}

Offering support to man in his or her intellectual effort is a new phenomenon typical of the Fourth Industrial Revolution. In the past, subsequent innovations allowed reducing substantially human physical effort undertaken to expand and improve the real world. Today, new technologies are deployed in the cognitive process. By expanding the scope of perception and context, increasingly bigger amounts of unstructured data are collected; in the first stage of the cognitive process these data are processed to obtain information from IT systems, robots, and bots. The second stage in the process consists in knowledge generation and use. Algorithms programmed by humans and used in digital technologies bring in knowledge, which may be generated in accordance with universally accepted ethical principles or infringe them. Irrespective of the motivation that drives people who use digital technologies, collected information may be regarded as knowledge because robots and bots have been noticed to be able to acquire expanded information, examine it and formulate conclusions. It is INDUSTRIAL KNOWLEDGE, which supplements knowledge traditionally generated by people, i.e. HUMAN KNOWLEDGE, and the two of them come together to form augmented knowledge. Only a human being - seeking his/her position in the aquarium carved in stone - is able to make references to the axiological system and shape his/her own ethical and altruistic 
attitudes. By exhibiting individual wisdom, man can use available knowledge for the benefit of himself or herself and of the community.

\section{References}

1. AI - a brand for Germany (2018). Retrieved from: www.bundesregierung.de [accessed: 16.11.2018].

2. Appunn, K., Bieler, F., Wettengel, J. (2018). Germany's Energy consumption and power mix in charts. Clean Energy Wire 3.4.2018, Retrieved from: www.cleanenergywire.org [accessed: 24.10.2018].

3. Bughin, J., Catlin, T., Hirt, M., Willmott, P. (2018). Why digital strategies fail. McKinsey Quarterly, January.

4. Bertoncello, M., Husain, A., Möller, T. (2018). Setting the Framework for Car Connectivity and User Experience. McKinsey Quarterly, November.

5. Chafkin, M., Brustein, J. (2018). Why America Is So Scared of China’s Biggest Tech Company. Bloomberg 22.03.2018. Retrieved from: www.bloomberg.com [accessed: 22.03.2018].

6. Chmielecki, A. (1995). Filozofia Poppera. Analiza krytyczna. Wrocław: Wydawnictwo Uniwersytetu Wrocławskiego.

7. Döpfner, M. (2018). Internetowy krezus Jeff Bezos. Die Welt-Gazeta.pl 16.10.2018. Retrieved from: www.gazeta.pl [accessed: 24.10.2018].

8. Downes, L. (2011). The Law of Disruption Occupies Wall Street. Forbes 16.10.2011. Retrieved from: www.forbes.com [accessed: 14.02.2017].

9. Ford, M. (2015). Rise of the Robots. Technology and the Threat of a Jobless Future. New York: Basic Books.

10. France's Overall Energy Mix. Planete Energies 27.08.2018. Retrieved from: www.planeteenergies.com [accessed 24.10.18].

11. Garbicz, M. (2018). Społeczne i ekonomiczne skutki gospodarki cyfrowej, Warszawa, SGH, lecture on 23.10.2018. Retrieved from: https://ssl-kolegia.sgh.waw.pl/pl/KZiF/konferencje/ Strony/ Konferencje-Naukowe-KZiF.aspx [accessed: 2.12.2018].

12. Goran, J., LaBerge, L., Shrinivisan, R. (2017). Culture of digital age. McKinsey Quarterly, July.

13. Haskel, J., Westlake, S. (2018). Capitalism without Capital. The Rise of the Intangible Economy. Princeton-Oxford: Princeton University Press.

14. Henkel, Ch.H. (2018). Zuckerbergs «Ups» als Reaktion auf die Cambridge-Analytica-Affäre enttäuscht. Neue Zürcher Zeitung 21.03.2018. Retrieved from: www.nzz.ch [accessed: 21.03.2018].

15. Hoppe, T., Weddeling, B. (2018). „Das ist Überwachung” - Apple-Chef Tim Cook attakiert Google und Facebook. Handelsblatt 24.10.2018. Retrieved from: www.handelsblatt.com [accessed: 24.10.2018].

16. Hua, S., Jahn, T., Kerkmann, Ch., Matthes, S., Scheuer, S., Weddeling, B. (2018). Wie China bei der Künstlichen Intelligenz zur Supermacht aufsteigt. Handelsblatt 25.10.2018. Retrieved from: www.handelsblatt.com [accessed: 25.10.2018].

17. https://www.livinginternet.com/i/ii_ai.htm [accessed: 23.09.2018]. 
18. https://en.wikipedia.org/wiki/Cognitive_science [accessed: 09.03.19].

19. Kędzierski, R. Niepokorni nie mogq nawet jeździć pociągiem. Retrieved from: www.next.gazeta. pl [accessed: 02.06.2018].

20. Korab-Karpowicz, W.J. (2017). Harmonia społeczna. Warszawa: Państwowy Instytut Wydawniczy.

21. Kroeger, T. (2018). Robotics Technologies - A Sneak Peek to Silicon Valley. Magdeburg: BVL (conference materials).

22. Lessin, J. (2018). Don't give up on Snap. The Information 3.11.2018. Retrieved form: www. theinformation.com [accessed: 03.11.2018].

23. Magee, B. (1998). Popper. Warszawa: Prószyński i S-ka.

24. Nida-Rümelin, J., Weidenfeld, N. (2018). Wir sind hier die einzigen Menschen! Tagesspiegel 10.9.2018. Retrieved from: www.tagesspiegel.de [accessed: 02.11.2018].

25. Popper, K. (2002). The Logic of Scientific Discovery, 1959 edition, reprint. London - New York: Routledge Classics.

26. Popper, K.R. (2002). Objective Knowledge. An Evolutionary Approach. Warszawa: Wydawnictwo Naukowe PWN (Polish version).

27. Schatz, G. (2015). Echte Bildung anstatt nur Wissenvermitlung. Neue Zürcher Zeitung 17.04.2015. Retrieved from: www.nzz.ch [accessed: 15.04.2015].

28. Scheuer, S., Matthes, M. (2018). Es gibt Firmen, die Zeit in Brettspiele investieren, - wir machen Krankenwagen schneller. Handelsblatt 26.10.2018. Retrieved from: www.handelsblatt. com [accessed: 26.10.2018].

29. Scheutz, M. (2018). Autonomous Robots Need Ethical Competence. Berlin: BVL.

30. Sivaram, V. (2018). Taming the Sun. Innovations to Harness Solar Energy and Power the Planet. Cambridge: The MIT Press.

31. Sommer, U. (2018). Diese Zahlen zeigen, weshalb US-Tech-Konzerne immer mächtiger werden. Handelsblatt 15.08.2018. Retrieved from: www.handelsblatt.com [accessed: 15.08.2018].

32. Steingart, G. (2018). KI: Chinas Aufstieg zur Supermacht. Retrieved from: www.gaborsteingart. com [accessed: 18.12.2018].

33. Straube, F. (2018). Artificial Intelligence - Concepts, Potentials and Challenges in Logistics. Berlin: BVL (conference materials).

34. Tatarkiewicz, W. (1990). O szczęściu. Warszawa: PIW.

35. Trösch, T. (2018). Auch Roboter entwickeln Vorurteile. Handelsblatt 11.09.2018. Retrieved from: www.handelsblatt.com [accessed: 11.09.2018].

36. Volland, H. (in an interview with Ch. Koch), (2018). Theoretisch wäre es denkbar, auch Regelbrüche zu programmieren. brand eins 23.10.2018. Retrieved from: www.brandeins.de [accessed: 25.10.2018]. 